\title{
Body image in pregnancy: A qualitative study in Malta
}

\author{
Claire Galea ${ }^{1}$, Georgette Spiteri ${ }^{1}$
}

\begin{abstract}
AFFILIATION
1 Department of Midwifery, Faculty of Health Sciences, University of Malta, Msida, Malta
\end{abstract}

CORRESPONDENCE TO

Claire Galea. Department of Midwifery, Faculty of Health Sciences, University of Malta, Office 47, Msida, Malta. E-mail: claire.galea.17@ um.edu.mt

\section{KEYWORDS}

body image, perception, lifestyle adjustments, pregnancy, media, society

Received: 31 August 2021, Revised: 21 January 2022,

Accepted: 26 January 2022

\begin{abstract}
INTRODUCTION Body image refers to one's perception of their own appearance. This can be influenced by life experiences, including the experience of pregnancy. The purpose of this study was to explore pregnant women's views of self during their first pregnancy. The objectives included: exploring women's feelings and thoughts about their pregnant bodies; understanding if and how lifestyle adjustments influence women's body image; and recognizing the societal and media impacts on women's self-perception.

METHODS A qualitative research design was used. Eight women, who were recruited by purposive sampling from a general state hospital in Malta, were virtually interviewed using a self-designed, semi-structured interview schedule. Data were then thematically analyzed.

RESULTS Findings concluded that women's perceived level of attractiveness during pregnancy varied and a desire to
\end{abstract}

gain control over one's own appearance was exhibited. Pregnancy's lifestyle adjustments were difficult for some to uphold, challenging their body image. Moreover, unsolicited comments from society appeared to take their toll on some women's self-perception, encouraging social comparison. Additionally, despite participants' awareness of media's false depictions of pregnant women and their bodies, some could not help but question their pregnant appearance, as a result of this.

CONCLUSIONS Ultimately, despite the hardships met in terms of body image, participants were generally happy during their first pregnancy and were excited to meet their baby. The findings of this study provide important in-depth information on body image specific to pregnancy, emphasizing the importance of midwives educating and assessing pregnant women on their perception of their changed pregnant body.

\section{INTRODUCTION}

In the seminal work by Schilder (1935), the concept of body image (BI) was introduced as one's mental representation of self, including one's perception of their appearance ${ }^{1}$. This is based on one's self-impression, originating from central consciousness, which is influenced by personality, experiences, memory, association, and self-esteem ${ }^{1}$. Throughout one's lifetime, these influential factors tend to fluctuate, resulting in higher levels of body-distortion amongst women, than in men $^{2}$. Pregnancy has been described as an experience that is subject to body-distortion, potentially altering one's perception of their naturallydeviating body ${ }^{1}$.

As pregnancy brings physical changes with it, some women enjoy looking pregnant or having an increased breast size $^{3}$. However, a substantial number of women have a lack of appreciation for their changing bodily measurements, spotty skin, and hair thinning. It was further declared that while some women are fascinated by their changing appearance when looking in the mirror, others feel horrified by these changes as they feel that they are now less feminine. Despite these varying perspectives, changes in BI are an inevitable part of pregnancies ${ }^{3}$.

Moreover, pregnancy symptoms such as nausea, vomiting and cravings inevitably alter one's dietary intake in pregnancy, making women more prone to weight fluctuations and therefore BI issues ${ }^{4}$. While pregnancy contributes to an optimal time during which most women consider lifestyle adjustments including healthy eating, others do not hold back on their cravings ${ }^{5}$. This in turn contributes to some women reporting a lack of control over their appearance during pregnancy ${ }^{5}$. While some women have reported feeling unsure and confused about the effects of exercise during pregnancy and the implications this had on their $\mathrm{BI}^{4}$, 
others have asserted that their main aim of exercising during pregnancy was due to its role in weight control and improved mental well-being 6 .

Furthermore, pregnant women have also reported a low sexual desire which has also been associated with a negative perception of their body and anxiety about their partner's thoughts regarding their changing body during this time $e^{3,7}$. Indeed, it was revealed that $10 \%$ of women $(n=57 / 570)$ stop sexual activity during pregnancy ${ }^{7}$. Other contributing factors to this altered rate of sexual activity during pregnancy include maternal age, parity, psychological and socio-cultural factors ${ }^{7}$.

Indeed, social constructs and stereotypes create a discrepancy between the ideal female body and the natural pregnant body. Social pressures and constant surveillance amongst women are already significant, regardless of pregnancy, encouraging self-evaluation and uncertainty ${ }^{6}$. This is especially so in Western cultures where, due to being an accessible and obvious feature of judgement, appearance is a daily preoccupation and a social pressure in itself 6 . This explains the societal attention and society's entitlement to comment freely on one's pregnant body when a woman is visibly pregnant $t^{6,8}$.

Similarly, exposure to mass media is unavoidable and this in turn influences pregnant women's BI perceptions. Exposure to magazines and celebrity gossip appear to create two opposing emotions in women, involving comparison ${ }^{8}$. From one end, women felt satisfied knowing that despite their lower financial status, their lives were superior and less materialistic. Others felt occasionally disappointed and confused by the difference between their own pregnancy experience and the perfect picture painted by media ${ }^{8}$. Fortunately, women reported being aware of media's unrealistic and glamourized portrayals of celebrities and pregnant women, the economic aim and the disappointing focus on the ideal pregnant body, consisting of a petite shape, an accessory-like pregnant belly, and skinny arms and legs ${ }^{8,9}$.

The current study expands upon existing literature with the aim of exploring pregnant women's views of self during their first pregnancy, via three main objectives: 1) To explore women's feelings and thoughts about their pregnant bodies, 2) To understand if and how lifestyle adjustments' influence women's BI in pregnancy, and 3) To explore social and media influences on pregnant women's BI.

\section{METHODS}

A qualitative research design was used in this study, which allowed the researchers to collect rich data from the participants ${ }^{10}$. A purposive sample of eight women was selected via intermediaries for participation in this study. Participants were primigravid women of Maltese nationality, at thirty weeks of gestation onwards, who were currently experiencing a singleton pregnancy and were admitted at a local general hospital in Malta.

A self-designed semi-structured interview schedule was specifically designed by the researchers for the purpose of the study. This was then submitted and approved for use by the Faculty Research Ethics Committee (FREC) and by the University Research Ethics Committee Data Protection (UREC-DP). The interview schedule provided guiding questions and additional probes, which encouraged participants to contribute towards a rich conversation. The interview schedule was designed in both Maltese and English, allowing participants to choose their preferred language to speak in, given that Malta is a bilingual country. The interview scheduled was piloted before use in the actual study. Participants were asked to participate in a virtual interview given that the study was conducted during the COVID-19 pandemic to ensure safety for both the participants and the researchers. Audio-recording was carried out with participants' consent and participants' names were pseudonymized for confidentiality purposes.

The data generated in this study were then transcribed verbatim and analyzed using the six-step linear method of thematic analysis of Braun and Clarke ${ }^{11}$. The first step required the researcher to familiarize herself with the data collected, reading it multiple times. Next, initial codes from the data were generated, highlighting the interesting points. Thirdly, common concepts were listed and grouped into themes, which were further selectively reviewed as step four. The fifth step required the definition and naming of the themes, before finally creating an analysis report of the fully identified themes created $^{11}$

Methodological rigor was given significant importance throughout the research process. This was ensured by maintaining a continuous discussion amongst the researchers on evolving themes throughout the research process, increasing credibility. Secondly, research needed to be dependable, meaning that its findings are stable over varying times and conditions, and would repeat themselves if replicated. To ensure credibility and dependability, member checking was carried out by the researchers. This was done by double-checking the data transcribed with the audio recordings, and by confirming the audiorecording via email with the participants themselves after the interview.

\section{RESULTS}

The participants' age ranged from 23 and 37 years, with a mean age of 31 years. The gestational age during which the mothers were interviewed ranged from $33+1$ to 40 weeks. All mothers were Caucasian in ethnicity, and were in a stable, romantic relationship at the time of interview. The mothers' education level ranged from secondary to tertiary, and all women were employed. Additionally, none of the participants disclosed any previous or existing mental illness (Table 1). From thematic analysis, six main themes emerged (Table 2). 
Table 1. Participants' characteristics, University of Malta, 2021

\begin{tabular}{|c|c|c|c|c|c|c|}
\hline $\begin{array}{l}\text { Participants } \\
\text { (pseudonyms) }\end{array}$ & $\begin{array}{c}\text { Age } \\
\text { (years) }\end{array}$ & $\begin{array}{l}\text { Gestation } \\
\text { (weeks) }\end{array}$ & $\begin{array}{c}\text { Education } \\
\text { level }\end{array}$ & Employment & $\begin{array}{l}\text { Marital } \\
\text { status }\end{array}$ & $\begin{array}{l}\text { Spoken language } \\
\text { during interview }\end{array}$ \\
\hline Christina & 30 & 38 & Tertiary & Advertisement & Married & English \\
\hline Gaby & 33 & $36^{+5}$ & Tertiary & Speech language centre & Married & English \\
\hline Sheryl & 27 & $33^{+1}$ & Secondary & Receptionist & w/Partner & Maltese \\
\hline Isabella & 33 & $39^{+1}$ & Tertiary & Senior agricultural officer & Married & English \\
\hline Bette & 23 & 40 & Post-secondary & Office administrator & w/Partner & English \\
\hline Jane & 31 & $39^{+5}$ & Tertiary & Freelance conference interpretor & Married & Maltese \\
\hline Roberta & 37 & $38^{+6}$ & Tertiary & Social worker/psychotherapist & w/Partner & English \\
\hline Anna & 35 & $39^{+4}$ & Secondary & Hairdresser & Married & Maltese \\
\hline
\end{tabular}

Participants had no presence/history of concurrent mental illness.

Table 2. Summary of the generated themes and subthemes, University of Malta, 2021

\begin{tabular}{|c|c|c|}
\hline Themes & Subthemes & Excerpts \\
\hline \multirow{2}{*}{$\begin{array}{l}\text { Women's } \\
\text { experience of } \\
\text { pregnancy }\end{array}$} & $\begin{array}{l}\text { Overall experience of } \\
\text { pregnancy }\end{array}$ & $\begin{array}{l}\text { 'It turned out to be positive in that sense, cause all I had was tummy weight } \\
\text {... but it's overwhelming at times.' (Gaby) }\end{array}$ \\
\hline & $\begin{array}{l}\text { Physical and mental well- } \\
\text { being during pregnancy }\end{array}$ & 'I wasn't feeling mentally and physically well ...' (Jane) \\
\hline \multirow{2}{*}{$\begin{array}{l}\text { Women's } \\
\text { perception of } \\
\text { their pregnant } \\
\text { appearance }\end{array}$} & $\begin{array}{l}\text { Attractiveness and } \\
\text { acceptance }\end{array}$ & $\begin{array}{l}\text { 'I turned into this awkward-looking person ... you feel that you're not keeping } \\
\text { up your appearance.' (Anna) }\end{array}$ \\
\hline & $\begin{array}{l}\text { Perceptions of pregnancy } \\
\text { changes }\end{array}$ & $\begin{array}{l}\text { 'In the beginning, I got a lot of spots ... so my face was a bit of a sore point, } \\
\text { and covering it in foundation ... just makes it worse.' (Gaby) }\end{array}$ \\
\hline \multirow{2}{*}{$\begin{array}{l}\text { Pregnancy lifestyle } \\
\text { adjustments' } \\
\text { impact on BI }\end{array}$} & Dietary adjustments & $\begin{array}{l}\text { 'At the beginning, I was like, "Look, I'm eating and nothing" but at the end, I } \\
\text { felt it because I put on a lot of weight.' (Bette) }\end{array}$ \\
\hline & Physical activity & 'I didn't do any exercise. I didn't have the strength.' (Anna) \\
\hline \multirow[t]{3}{*}{$\begin{array}{l}\text { Society's influence } \\
\text { over BI }\end{array}$} & $\begin{array}{l}\text { Attention from society on } \\
\text { pregnant women }\end{array}$ & 'I would feel more self-conscious when I go out ...' (Anna) \\
\hline & $\begin{array}{l}\text { Comments from society on } \\
\text { pregnancy }\end{array}$ & $\begin{array}{l}\text { I think it's the effect of a small country, a small-knit community, the gossip ...' } \\
\text { (Roberta) }\end{array}$ \\
\hline & $\begin{array}{l}\text { Social comparison and } \\
\text { women's take from society }\end{array}$ & $\begin{array}{l}\text { 'Other pregnant womens' faces glowed ... but I would always look so pale.' } \\
\text { (Anna) }\end{array}$ \\
\hline \multirow[t]{2}{*}{$\begin{array}{l}\text { Media's influence } \\
\text { over BI }\end{array}$} & $\begin{array}{l}\text { Women's general views of } \\
\text { media }\end{array}$ & $\begin{array}{l}\text { 'It doesn't affect me that much, because I know they're portrayed like that } \\
\text { due to tricks and light.' (Isabella) }\end{array}$ \\
\hline & $\begin{array}{l}\text { Media comparison and } \\
\text { impact }\end{array}$ & $\begin{array}{l}\text { 'Social media does tend to picture pregnant women prettier ... and you say, } \\
\text { "Am I that pretty?"'. (Christina) }\end{array}$ \\
\hline \multirow{2}{*}{$\begin{array}{l}\text { Womanhood and } \\
\text { bond with the } \\
\text { unborn baby }\end{array}$} & 'Being at one with the baby' & $\begin{array}{l}\text { 'I don't mind what happens to my body, as long as the baby is okay.' } \\
\text { (Christina) }\end{array}$ \\
\hline & Womanhood & $\begin{array}{l}\text { 'The woman is the only human being who carries another human inside! You } \\
\text { have a lot to feel special about!' (Sheryl) }\end{array}$ \\
\hline
\end{tabular}

BI: body image. 


\section{Theme 1: Women's experience of their pregnancy}

Pregnancy presented itself to most women as a whirlwind of experiences relating to their BI. Apart from physical changes occurring, women also spoke about how their BI affected their mental health.

'The pregnancy came with many highs and lows ... there are a lot of changes happening. Your diet, energy, the way you feel inside, the hormones, everything.' (Isabella, p.1, l.8)

Amongst the challenges encountered were the COVID-19 pandemic's impact on the women's upkeep and perception of self, as well as the lack of control they felt they had over their own body and their pregnancy experience.

'With Covid, I had nowhere to dress up for ... you feel a bit down that you're in joggers all the time.' (Gaby, p.3, l.15)

When asked about their general perceptions of their pregnant bodies, some expressed feeling less attractive than their pre-pregnant self, using words with negative connotations like 'bigger' and 'feeling fat' in their narratives. Despite this, all women were accepting of the inevitable change, with some reminding themselves that their physical appearance wasn't a reflection of bad health, and that the physical changes experienced were only going to last for the duration of the pregnancy.

'I am creating a human being ... I'm not in bad health.' (Christina, p.13, l.7)

Additionally, the importance of the partner's support and opinion on their counterparts' attractiveness was deemed as impactful on women's BI.

'It's his opinion of me that counts ...' (Christina, p.3, 1.8)

Theme 2: Women's perception of their pregnancy changes The women participating in this study all reacted differently to physical changes brought about by pregnancy. The majority of participants particularly viewed their growing belly in a positive light.

'Seeing it getting bigger, I was loving it ... It was the only thing I wanted to grow.' (Isabella, p.3, l.31)

As for breast changes, while some considered themselves unaffected by this change, others were quite satisfied with their increased size, especially those who were previously small-chested before pregnancy. On the other hand, two women reported discontent with their increased breast size, one of them stating that she felt 'like a cow.' (Isabella, p.3, 1.25).

Other women brought up other changes that they were not very fond of, including stretch marks, a protruding belly button, acne, and hair changes. One woman expressed how her loss of hair, greatly impacted her image and identity.

'Its' part of my identity. I have big hair, it's part of who I am. And it's dying out ... so yes, that affected me.' (Roberta, p.5, l.11)

The issue of weight gain and weight loss was brought up by several women, who felt a lack of control over their changed body.

'I ended up putting on around 38 kilos ... The weight affected me the most ... I used to be skinny.' (Bette, p.2, l.22)

Two participants, however, shared that they were quite unaffected by these changes, prioritizing physical health and spiritual wellbeing over appearance. One participant added that personality and age play a role in prioritizing what is mostly important.

'The physical changes didn't affect me much .... because I view the body ... in a very spiritual way ... By character and by age, you learn to prioritize what is important ...' (Roberta, p.3, 1.23)

Theme 3: Pregnancy lifestyle adjustments' impact on BI The majority of women managed to maintain a well-balanced diet. One participant however, did not limit her intake, with consequences to her BI.

'At the beginning, I was like, "Look, I'm eating and nothing" but at the end, I felt it because I put on a lot of weight.' (Bette, p.4, l.21)

When asked about physical activity during pregnancy, some women explained how they adjusted or stopped their exercise routine together with their sexual activity.

'I didn't do any exercise. I didn't have the strength.' (Anna, p.4, 1.4)

The women that did exercise during pregnancy described how it helped them physically and psychologically.

'It helps you mentally to feel better, it gave me more stamina.' (Isabella, p.4, 1.25)

Roberta's narrative highlighted a sense of confusion, potentially brought about by a lack of information with regard to the safety of exercise during pregnancy.

'When I'd dance ... I would have to think, "Can I do this?" It was confusing. I was never sure about what was safe and what wasn't' (Roberta, p.6, 1.7)

When addressing sexual health and lifestyle, five women expressed a continuous sexual relationship with their partner or husband, however, they reported a decrease in frequency of sexual encounters, as well as a general physical and mental shift relating to sexuality.

'From a sexual aspect, there was a big change. There was much less activity and I think it was more of a mental thing ... even from my partner's side ... I think he used to see me as being vulnerable in a way. There was a certain mental block. I felt that. Physically as well ... as I was uncomfortable.' (Jane, p.4, 1.7)

Two couples expressed how they completely stopped being intimate with their partners, stating, however, that this did not affect them as a couple. A number of participants emphasized the importance of open communication with their partner in these instances.

'Zero sexual activity. Not because I wasn't comfortable but I would always be feeling sick. But as a couple, we remained the same regardless.' (Anna, p.4, 1.23)

\section{Theme 4: Society's influence over BI in pregnancy}

Some participants described how a pregnant woman's body 
alters society's behavior. Participants appeared to be quite satisfied with society's increased concern to help when visualizing a pregnant abdomen.

'I used to catch the bus and I noticed that ...when I was showing, everyone would stand up ... people are much nicer to me.'(Bette, p.5, 1.14)

Two participants added that they wanted their bump to show in order to justify their increased weight in the eyes of society.

'At the beginning, I wasn't that huge so maybe, they'd think I've just gotten fat and you just want it to grow to show that it's a baby and, no, I'm not getting fatter.' (Isabella, p.4, 1.5)

Many women experienced both negative and positive comments relating to their pregnant appearance. Unfortunately, some women also reported being negatively affected and unappreciative of society's intrusive and unsolicited comments.

I had one or two comments from acquaintances like, "How large! You grew a lot!" I know ... Those comments, they could have avoided.' (Isabella, p.8, 1.1)

'There were people who told me "Are you sure you're not having two?", when they saw my big belly.' (Jane, p.6, 1.5)

Some acknowledged how certain comments and gossip are defining characteristics of Maltese society.

'That's the Maltese, what they see, they need to comment on.' (Isabella, p.8, 1.6)

'I think it's the effect of a small-knit community, the gossip ...' (Roberta, p.7, 1.18)

Women described instances when they would compare themselves to others, such as friends and other pregnant women, which would in turn influence women's perception of their BI, and at times bring about unnecessary stress.

'My friends are all skinny and I'm skinny ... well I used to be skinny. So, putting on weight, I feel like I will sort of have to compete again and make an effort ... I do feel there's pressure when it comes to women.' (Bette, p.5, 1.6)

\section{Theme 5: Media's influence over BI in pregnancy}

Despite mentioning its benefits and great reach and influence on the general public, most participants were fully aware of media's potentially harmful unrealistic portrayals of BI, especially in pregnancy. Sexualization of women and their bodies, including pregnant bodies was commented on by one participant, who expressed her disappointment and disgust.

'When they're trying to sell, they'll portray this goddess ... even sexualizing the body, the perfect shape and lingerie photos ... it disgusts and disappoints me.' (Roberta, p.9, 1.17)

Some women expressed their awareness of the realities of women's bodies in pregnancy through their own life experiences.

II used to see adverts and then I used to go my appointment at hospital, and not one person looked that way.' (Bette, p.8, 1.1)

Most women claimed to be affected at times, despite their awareness, comparing themselves to the media's portrayals.
'Everyone's skin looks perfect and my face would be full of spots.' (Gaby, p.12, 1.5)

However, some women claimed to be unaffected, one of which viewing herself as superior to what appears in the media.

'A celebrity cannot eat chocolate. If my baby tells me to eat, I can eat it.' (Sheryl, p.11, 1.2)

\section{Theme 6: Womanhood and bond with the unborn baby}

Despite the overwhelming experience of pregnancy and its rapid changes, all women created an undeniable bond with their baby, which they state, compensated for any negative aspects of pregnancy and their altered BI.

'I have to work on letting go of being one with the baby. I'll miss my belly, feeling her inside me. In my experience, having the opportunity to feel one with another human being is priceless.' (Roberta, p.10, 1.5)

All women also felt fortunate and proud of their womanhood and their capability in experiencing this 'miraculous' journey of pregnancy.

II am creating a human being, which is a miracle ... For all the changes we experience, we get a human being for life. I think that us women are quite strong ... and very capable.' (Christina, p.13, l.7)

\section{DISCUSSION}

Pregnancy is a time of many changes. Overall, the study's participants viewed their pregnancy experience as predominantly positive, with some negative aspects which impacted on the perception of their BI. This was consistent with findings from a systematic review ${ }^{12}$, with both highlighting a lack of control women felt they had over their body throughout their pregnancy.

Some participants described their pregnancy as 'lonely', 'difficult' and 'overwhelming' at times, mainly due to the COVID-19 pandemic and its restrictions. In line with this, an Italy-based study reported higher rates of anxiety and psychological disturbances brought about by social isolation and decreased family interactions during pregnancy ${ }^{13}$. These feelings might have further contributed to negative feelings about women's BI in this study.

Pregnancy brought about a spectrum of different perceptions of $\mathrm{BI}$, ranging from body satisfaction to dissatisfaction. Participants' perception of their pregnant appearance in the current study varied with some feeling just as attractive and others feeling less attractive than before their pregnancy, with the latter case leading to feelings of disappointment. Similar to other literature, participating women also highlighted the importance of their partner's support and opinions of their counterparts' attractiveness $s^{3,6,8}$. Most women were particularly satisfied with their increased breast size and a growing belly. Interestingly, the former feature was commented on by small-chested women, which was also the case in other studies ${ }^{6}$. Several participants also stated their disappointment when their belly did not show, 
hindering them from looking officially pregnant ${ }^{6,8}$.

Some participants in the current study did not feel as excited when looking at themselves in the mirror, reporting that they felt overwhelmed with their changed BI. Pregnancy changes that appeared to dissatisfy women were acne and hair thinning, while stretch marks were not as concerning to women in the current study, when compared to other studies ${ }^{3}$. A sense of loss of identity linked to pregnancy changes identified in the findings was also consistent ${ }^{6,8}$. Ultimately, women accepted their changing bodies, prioritizing their baby's health over aesthetics ${ }^{8}$.

Pregnancy lifestyle adjustments and their impact on BI also varied. Some participants maintained a healthy diet while others indulged in their cravings, similar to other findings ${ }^{4,5}$. In the current study, the latter led to weight gain which affected women's BI. Additionally, a decrease or complete cessation of exercise in pregnancy, mainly due to fatigue and nausea was reported ${ }^{6}$. When it came to sexual intercourse during pregnancy, a reduced frequency of sexual encounters was reported, consistent to other international research ${ }^{7,14,15}$. Interestingly, women's confusion and fear about whether any physical activity is beneficial or harmful in pregnancy, may imply a lack of information giving in this regard, which has implications for midwives in particular.

Increased societal attention with increased gestation was reported by the women in this study and others ${ }^{6}$, resulting in different reactions. While some felt self-conscious, others wanted to show it off in order to let society know they were pregnant. The latter was consistent with other studies especially since this would help with speculations regarding women's weight gain ${ }^{6,8,12}$. A society's need to advise women on how to look and feel, as well as the need to 'give their two cents', was in line with the current findings. Additionally, participants from this study suggested that some women can be negatively impacted by certain comments made about their size ${ }^{6}$.

What separates this current study from other international research, is Malta's unique characteristics, especially regarding its small population and the impact of a face-to-face community. This small community notion states that a small Mediterranean population emphasizes social pressures that encourage feelings of self-evaluation ${ }^{16}$. This was evident in the current study and participating women highlighted the need for society to be less intrusive. Upward and downward social comparison ${ }^{17}$ was also brought up by participants, where women compared themselves to their friends, feeling either better or worse about themselves, and their BI during pregnancy. The general pressure of females and their bodies regardless of pregnancy was also brought up in this current study and in others ${ }^{6,8}$.

When it came to media's influence over BI in pregnancy, participants were aware of the unrealistic portrayals of pregnant women on media and their drive for economic gain, which enforces glamourization and sexualization of women, including pregnant women ${ }^{8}$. This consistent need of 'sexualizing the body' (Roberta) that was commented on by participants, was addressed in the Sexual Objectification Theory ${ }^{9}$. This notion created feelings of disgust and disappointment as found in the current study. Upward and downward comparisons to the media were described by the study's participants as well as other studies ${ }^{6,17}$. Some found themselves upward comparing themselves to media, despite knowing about media's unrealistic portrayals. On the other hand, some downward compared themselves as relatively superior to celebrities' lack of freedom.

Ultimately, despite the challenges that pregnancy brings along with it, all women managed to bond with their unborn baby and prioritized the baby's well-being over theirs ${ }^{6}$. Women in the present study, additionally expressed excitement to meet their baby, adding that they will miss their pregnancy, irrespective of its impact on their BI.

\section{Strengths and limitations}

This study has limitations. Firstly, the small sample size limits generalizability of the generated findings even though, being a qualitative study, this was never the aim. Given the aim of the study, it would have been interesting to include other factors such as women's BMI and the reason for admission as part of the selection criteria of the participants, as these could have influenced women's perceptions of their BI. Furthermore, the interview schedule did not focus on each trimester, therefore women's perception of their BI was not specified to a specific gestation unless acknowledged by women themselves. The use of a self-designed interview schedule may be viewed as a limitation in itself. One must also note that conducting virtual interviews could have resulted in missing some non-verbals. Despite the online barrier, a social desirability bias could have also presented, due to the interviewer's presence. This bias is more prone in pregnant participants due to society's expectation for them to be healthy pregnant women ${ }^{8}$.

The study's strength was the self-designed, semistructured interview that was specifically designed for the purpose of the study, after a thorough review of the literature. This allowed women to speak openly and at length.

\section{Implications}

This study acknowledges the important role of clinicians, particularly midwives who are given a unique opportunity to develop a trusting relationship with women, continuously assess a pregnant woman's psychological well-being, and increase women's awareness about available psychological and social support services, referring appropriately when necessary.

Literature suggests that although a discussion on BI may trigger anxiety on excessive weight gain or loss in pregnant women, it could be a highly effective method of screening any underlying or developing mental health issues, such as 
anxiety, depression and eating disorders ${ }^{3,8}$. Whether this discussion is tackled during pre-conception counselling or antenatal classes, women and their partners should be aware of pregnancy's potential impact on their surrounding relationships and daily lifestyle. This creates the potential of preconception clinics in Malta, to be run by midwives, also including others such as nutritionists, psychologists, and other women who have personally struggled with body image during pregnancy and could share their own experiences and personal advice.

The homogeneity of the study's participants, as well as the lack of local literature conducted on BI during pregnancy, calls for further research. This would potentially take into account: BMI or trimester-specific BI, comparison of BI between women with and without a partner, as well as different perceptions between Maltese and foreign women, given our multicultural society.

\section{CONCLUSIONS}

Overall, women viewed themselves as less attractive during pregnancy, and a desire to gain control of the inevitably changing body was emphasized. However, acceptance of their naturally-deviating body and support from their partners was exhibited by all participants. A growing abdomen was generally perceived in a positive light amongst the study participants. The majority of women managed to adjust their daily activities to pregnancy, with some struggling to maintain exercise, sexual activity and a healthy weight. With increased attention from society, women seemed to be impacted both positively and negatively. Unsolicited comments were experienced by most, who emphasized a small society's potential impact on one's well-being. Several women compared themselves to others in society, highlighting the social pressures put on pregnant women. Moreover, all women were aware of the influence of media and their inaccurate depictions of the pregnant female form, with some women's BI being somewhat impacted. Despite this, all women concluded that despite pregnancy's impact on BI, women appreciated their pregnancy and their body's ability to change, whilst they looked forward to meeting their baby.

\section{REFERENCES}

1. Schilder P. The Image and Appearance of the Human Body: Studies in the Constructive Energies of the Psyche. Kegan Paul; 1935. Psyche Monographs no. 4.

2. Kevin Thompson J, Thompson CM. Body size distortion and self-esteem in asymptomatic, normal weight males and females. Int J Eat Disord. 1986;5(6):1061-1068. doi:10.1002/1098108x(198609)5:6<1061::aid-eat2260050609>3.0.co;2-c

3. Watson B, Broadbent J, Skouteris H, Fuller-Tyszkiewicz M. A qualitative exploration of body image experiences of women progressing through pregnancy. Women Birth. 2016;29(1):72-79. doi:10.1016/j.wombi.2015.08.007

4. Dacach Fernandez Marchi J. Diet and dietary patterns during pregnancy in nulliparous women in Ireland: a longitudinal cohort study. Dissertation. University of Dublin Trinity College; 2020. Accessed January 21, 2022. http://www.tara. tcd.ie/handle/2262/92712

5. Padmanabhan U, Summerbell CD, Heslehurst N. A qualitative study exploring pregnant women's weight-related attitudes and beliefs in UK: the BLOOM study. BMC Pregnancy Childbirth. 2015;15:99. doi:10.1186/s12884-015-0522-3

6. Deighton-Smith N. BODY IMAGE, HEALTH, AND PHYSICAL ACTIVITY IN PREGNANT WOMEN: A COMPOSITE ANALYSIS. Dissertation. Leeds Metropolitan University; 2014. Accessed January 21, 2022. https://eprints.leedsbeckett.ac.uk/id/ eprint/2644/1/Final_thesis_redactedversion.pdf

7. Afshar Y, Nguyen ML, Mei J, Grisales T. Sexual health and function in pregnancy. Contemporary Ob/Gyn. 2017;62(8):24-30. Accessed January 21, 2022. https:// www.sasharg.com.ar/descargas/Actualizaciones/Sexual\%20 health\%20and\%20function\%20in\%20pregnancy.pdf

8. Hopper KM. BUMPING UP THE BODY: EXAMINING THE IMPACT OF CELEBRITY GOSSIP MAGAZINES ON BODY IMAGE DURING PREGNANCY. Dissertation. University of Missouri; 2010. Accessed January 21, 2022. https://mospace. umsystem.edu/xmlui/bitstream/handle/10355/12006/ research.pdf?sequence=3\&isAllowed $=y$

9. Fredrickson BL, Roberts TA. Objectification Theory: Toward Understanding Women's Lived Experiences and Mental Health Risks. Psychol Women Q. 1997;21(2):173-206. doi:10.1111/j.1471-6402.1997.tb00108.x

10. Polit DF, Beck CT. Nursing research: Generating and assessing evidence for nursing practice. 10th ed. Wolters Kluwer; 2017.

11. Braun V, Clarke V. Using thematic analysis in psychology. Qual Res Psychol. 2006;3(2):77-101. doi:10.1191/1478088706qp063oa

12. Hodgkinson EL, Smith DM, Wittkowski A. Women's experiences of their pregnancy and postpartum body image: a systematic review and meta-synthesis. BMC Pregnancy Childbirth. 2014;14:330. doi:10.1186/1471-2393-14-330

13. Saccone G, Florio A, Aiello F, et al. Psychological impact of coronavirus disease 2019 in pregnant women. Am J Obstet Gynecol. 2020;223(2):293-295. doi:10.1016/j.ajog.2020.05.003

14. Fernández-Carrasco FJ, Rodríguez-Díaz L, GonzálezMey U, Vázquez-Lara JM, Gómez-Salgado J, ParrónCarreño T. Changes in Sexual Desire in Women and Their Partners during Pregnancy. J Clin Med. 2020;9(2):526. doi: $10.3390 / \mathrm{jcm} 9020526$

15. Khalesi ZB, Bokaie M, Attari SM. Effect of pregnancy on sexual function of couples. Afr Health Sci. 2018;18(2):227234. doi:10.4314/ahs.v18i2.5

16. Peristiany JG, ed. Honour and Shame: The Values of Mediterranean Society. The University of Chicago Press; 1966.

17. Festinger L. A Theory of Social Comparison Processes. Human Relations. 1954;7(2):117-140. 
doi:10.1177/001872675400700202

\section{CONFLICTS OF INTEREST}

The authors have completed and submitted the ICMJE Form for Disclosure of Potential Conflicts of Interest and none was reported.

FUNDING

There was no source of funding for this research.

ETHICAL APPROVAL AND INFORMED CONSENT

Ethical approval was obtained from the Faculty Research Ethics

Committee (FREC) and the University Research Ethics Committee - Data
Protection (Approval number: V_110220204453; Date: 22/10/2020). Informed consent was obtained from the participants.

\section{DATA AVAILABILITY}

The data supporting this research are available from the authors on reasonable request.

\section{PROVENANCE AND PEER REVIEW}

Not commissioned; externally peer reviewed. 